\title{
Increased Risk of Renal Deterioration Associated with Low e-GFR in Type 2 Diabetes Mellitus Only in Albuminuric Subjects
}

\author{
Shu Meguro, Toshikatsu Shigihara, Yusuke Kabeya, Masuomi Tomita and Yoshihito Atsumi
}

\begin{abstract}
Objective The significance of estimated glomerular filtration rate (e-GFR) in diabetic nephropathy has yet to be clearly determined. We therefore compared albuminuria and e-GFR for usefulness in predicting progressive decline in renal function.

Methods A total of 1,303 subjects with type 2 diabetes mellitus whose e-GFR was more than $30 \mathrm{~mL} / \mathrm{min} /$ $1.73 \mathrm{~m}^{2}$ were followed for three years. Associations of clinical staging based on AER and that based on eGFR with progression of renal insufficiency (e-GFR $<30 \mathrm{~mL} / \mathrm{min} / 1.73 \mathrm{~m}^{2}$ ) were evaluated.

Results On univariate analysis, both clinical stages based on e-GFR and AER were significant variables ( $\mathrm{p}<$ 0.05). On multiple logistic regression analysis, the odds ratio for macroalbuminuria was 132.3 , and that for microalbuminuria was 10.3 while that for e-GFR less than $60 \mathrm{~mL} / \mathrm{min} / 1.73 \mathrm{~m}^{2}$ was 9.0 for further deterioration of renal function. On the other hand, subjects without albuminuria exhibited a rate of disease progression of less than $1 \%$ irrespective of e-GFR level.

Conclusions Both albuminuria and reduced e-GFR are significant and independent risk factors for further deterioration of diabetic nephropathy, though albuminuria had a greater odds ratio than reduced e-GFR for deterioration of renal function over a three-year period. e-GFR exhibited additive risk for deterioration of diabetic nephropathy within three years only when albuminuria was present.
\end{abstract}

Key words: chronic kidney disease, diabetic nephropathy, albuminuria, risk factor

(Inter Med 48: 657-663, 2009)

(DOI: 10.2169/internalmedicine.48.1865)

\section{Introduction}

Diabetic nephropathy is the leading cause of end-stage renal disease (ESRD), and the number of individuals requiring chronic dialysis or renal transplantation is still increasing in most countries (1). Clinical staging of diabetic nephropathy is based mainly on urinary albumin excretion rate (AER) and, in the advanced stage, reduced glomerular filtration rate (GFR), as well, as follows: stage 1, no evidence of microalbuminuria; stage 2, microalbuminuria; stage 3 , macroalbuminuria; stage 4, reduced GFR; and stage 5, dialysis or renal transplantation. It is assumed that the progression of diabetic nephropathy to ESRD is more common in the advanced clinical stage. Yokoyama et al and Ueda et al inde- pendently reported the rate of progression to ESRD in Japanese subjects with chronic renal failure $(2,3)$. Hasslacher et al estimated that about $60 \%$ of diabetic subjects with proteinuria progressed to renal failure during 5-year follow-up (4).

On the other hand, the concept of chronic kidney disease (CKD), defined as either reduced estimated-GFR (e-GFR) or proteinuria, has been emerging. Numerous findings have shown that reduced GFR, as estimated by the abbreviated Modification of Diet in Renal Disease (MDRD) equation, is independently associated with either increased cardiovascular disease (CVD) risk or mortality (5-8). Since CKD has come to be widely accepted as an independent risk factor for cardiovascular disease, the Japanese Society of Nephrology announced a new coefficient of the abbreviated MDRD 
equation modified for Japanese subjects in June 2007 (9). However, since the earlier stages of diabetic nephropathy are not diagnosed based on GFR, discrepancy between e-GFR and AER has often left physicians with the question of whether e-GFR adds further risk of deterioration of renal function in subjects with diabetic nephropathy without albuminuria.

In this study, we prospectively examined a hospital-based study cohort to evaluate the significance of both the clinical staging of diabetic nephropathy based on the level of AER and staging based on e-GFR for a three-year progression of renal dysfunction.

\section{Methods}

All of the subjects admitted to our hospital for a 2-week diabetic education program from January 1999 to December 2004 were study candidates. Those subjects whose e-GFR was less than $30 \mathrm{~mL} / \mathrm{min} / 1.73 \mathrm{~m}^{2}$ and those with a strong suspicion of etiology of renal disease other than diabetic nephropathy (e.g. glomerulonephritis) were excluded. Subjects were treated for their diabetes mellitus and, when necessary, for their co-existing diseases as well in our outpatient clinics at intervals of one to four months depending on the status of each disease. Of the 1,901 subjects, 7 died (5 due to cancer, 1 acute myocardial infarction, and 1 sudden death), 38 moved to other medical facilities for medical or personal reasons, and 553 withdrew for unknown reasons within three years. Data three years after initial inclusion in the study were available for a total of 1,303 subjects (follow-up rate $68.5 \%$ ).

Blood collection after overnight fast was performed in the early morning of Day 2 of hospitalization. Serum fasting glucose, total cholesterol, HDL cholesterol, triglycerides, and serum creatinine, which were determined by enzymatic methods, and several other biochemical assays were performed with autoanalyzers. Serum creatinine concentrations three years after admission were evaluated in the outpatient clinic. Data obtained soon after the end of the three-year period were adopted. Almost all subjects were evaluated within four months after the end of the three-year period. HbA1c levels at admission were determined by highperformance liquid chromatography. Twenty-four-hour urine collection was performed from Day 2 to Day 3 during hospitalization. Microalbuminuria was defined as $20 \mu \mathrm{g} / \mathrm{min}$ to $200 \mu \mathrm{g} / \mathrm{min}$ and macroalbuminuria as more than $200 \mu \mathrm{g} / \mathrm{min}$ AER for 24-hour urine collection. e-GFR $\left(\mathrm{mL} / \mathrm{min} / 1.73 \mathrm{~m}^{2}\right)$ was calculated as $0.741 \times 175 \times \mathrm{Age}^{-0.203} \times \mathrm{Cr}^{-1.154}$ (with further multiplication by 0.742 for female subjects) using the equation provided by the Japanese Society of Nephrology (9). All subjects underwent funduscopic examination by trained ophthalmologists during or just before admission. Past history of CVD was checked through medical records or detailed medical interview. Prior histories of myocardial infarction, coronary intervention, and ischemic stroke, as well as performance of amputation or arterial intervention because of lower limb ischemia, were regarded as history of CVD. Progression of diabetic nephropathy was defined as e-GFR less than $30 \mathrm{~mL} / \mathrm{min} / 1.73 \mathrm{~m}^{2}$ after three years. Development of CVD was defined as the onset of myocardial infarction, coronary intervention, and major stroke, as well as lower limb ischemia within the 3-year period.

Continuous variables are expressed as the mean \pm SD. Student's unpaired t-tests and $\chi^{2}$ tests were performed to evaluate differences in mean values and prevalence, respectively. Multiple logistic regression analysis with compulsory input was performed in three ways to evaluate independent odds ratios of variables. Model A included e-GFR and AER as continuous variables, while Model B and Model C also included clinical staging based on either e-GFR or AER, since physicians usually use them to evaluate patient risk. Also, multiple logistic regression analysis for the development of CVD was performed by the clinical staging based on either e-GFR or AER. $\mathrm{p}<0.05$ was considered statistically significant. All analyses were performed using SPSS 13.0J statistical software.

\section{Results}

The baseline characteristics of this study cohort and the dropout subjects are shown in Table 1. The average age of this study cohort was around 60 years, and two-thirds were male subjects, with an average of about ten years' duration of diabetes. Mean systolic blood pressure was $132 \mathrm{mmHg}$ and mean diastolic blood pressure $75 \mathrm{mmHg}$. Mean $\mathrm{HbAlc}$ was $8.7 \%$. About $30 \%$ of study participants had diabetic retinopathy and $10 \%$ had prior history of CVD. The Dropout subjects were dominantly male, younger with shorter duration of the disease, higher smoker ratio, less serum creatinin level, and less frequent of prior CVD. The baseline characteristics of study participants were compared in Table 2 between two groups: subjects whose e-GFR declined to less than $30 \mathrm{~mL} / \mathrm{min} / 1.73 \mathrm{~m}^{2}$ after three years, and those whose e-GFR was more than $30 \mathrm{~mL} / \mathrm{min} / 1.73 \mathrm{~m}^{2}$ after three years. On univariate analysis, BMI, duration of diabetes mellitus, systolic blood pressure, diastolic blood pressure, HbA1c, total cholesterol level, hemoglobin concentration, serum creatinine, e-GFR at baseline, clinical stage based on level of AER, renin-angiotensin system (RAS) blockade medication, and prior history of CVD were significant variables.

On multiple logistic regression analysis, in Model A, HbA1c, systolic blood pressure, and both e-GFR and AER at baseline were independently associated with three-year GFR decrease to less than $30 \mathrm{~mL} / \mathrm{min} / 1.73 \mathrm{~m}^{2}$. In model $\mathrm{B}$, the presence of macroalbuminuria and e-GFR less than 60 $\mathrm{mL} / \mathrm{min} / 1.73 \mathrm{~m}^{2}$ at baseline were still independent risk factors for three-year renal deterioration (Table 3). In Model C, odds ratio was highest when macroalbuminuria was present, with risk being 132 times higher, while that of e-GFR less than $60 \mathrm{~mL} / \mathrm{min} / 1.73 \mathrm{~m}^{2}$ was 9.0 .

However, as shown in Fig. 1, subjects without albuminuria exhibited a rate of disease progression of less than $1 \%$ 
Table 1. Baseline Characteristics of the Study Cohort and the Dropout Subjects

\begin{tabular}{|c|c|c|c|}
\hline & stady paticipants & dropouts & $p$ value \\
\hline age $(y / o)$ & $60.0 \pm 8.9$ & $57.4 \pm 8.9$ & $\mathrm{p}<0.01$ \\
\hline gender (male/female) & $894 / 409$ & $409 / 144$ & $\mathrm{p}<0.05$ \\
\hline BMI & $23.6 \pm 3.8$ & $23.9 \pm 3.9$ & n.s. \\
\hline duration of diabetes mellitus (year) & $10.5 \pm 8.3$ & $8.3 \pm 7.5$ & $\mathrm{p}<0.01$ \\
\hline systolic blood pressure $(\mathrm{mmHg})$ & $132 \pm 17.6$ & $131 \pm 17.5$ & n.s. \\
\hline diastolic blood pressure $(\mathrm{mmHg})$ & $74.5 \pm 10.8$ & $75.2 \pm 11.2$ & n.s. \\
\hline fasting plasma glucose (mmol/L) & $9.66 \pm 2.89$ & $9.71 \pm 3.44$ & n.s. \\
\hline $\mathrm{HbA1c}(\%)$ & $8.7 \pm 1.8$ & $8.8 \pm 1.9$ & n.s. \\
\hline total cholesterol $(\mathrm{mmol} / \mathrm{L})$ & $5.28 \pm 0.95$ & $5.25 \pm 1.09$ & n.s. \\
\hline HDL cholesterol (mmol/L) & $1.35 \pm 0.38$ & $1.32 \pm 0.39$ & n.s. \\
\hline triglyceride (mmol/L) & $1.62 \pm 1.46$ & $1.63 \pm 1.31$ & n.s. \\
\hline hemoglobin $(\mathrm{g} / \mathrm{L})$ & $143 \pm 14$ & $144 \pm 14$ & $p<0.05$ \\
\hline serum creatinin $(\mu \mathrm{mol} / \mathrm{L})$ & $65.4 \pm 44.2$ & $63.6 \pm 16.2$ & $p<0.01$ \\
\hline $\begin{array}{l}\text { estimated GFR }(30-59 / 60-89 / 90< \\
\left.\mathrm{mL} / \mathrm{min} / 1.73 \mathrm{~m}^{2}\right)\end{array}$ & $151 / 804 / 348$ & $171 / 331 / 51$ & n.s. \\
\hline $\begin{array}{l}\text { diabetic nephropathy (none/ } \\
\text { microalbuminuria/ macroalbuminuria) }\end{array}$ & $803 / 385 / 115$ & $384 / 139 / 31$ & n.s. \\
\hline $\begin{array}{l}\text { diabetic retinopathy (none/ } \\
\text { background/ more advanced stage or } \\
\text { prior photocoagulation) }\end{array}$ & $926 / 250 / 127$ & $420 / 83 / 50$ & n.s. \\
\hline $\begin{array}{l}\text { prior cardiovascular disease } \\
\text { (none/positive) }\end{array}$ & $1183 / 120$ & $521 / 32$ & $\mathrm{p}<0.05$ \\
\hline present smoker (\%) & 24.3 & 31.4 & $p<0.01$ \\
\hline
\end{tabular}

Estimated GFR is subdivided into $30-59 / 60-89 / 90<\mathrm{mL} / \mathrm{min} / 1.73 \mathrm{~m}^{2}$, diabetic nephropathy into none/ microalbuminuria/ macroalbuminuria, and diabetic retinopathy into none/ background/ more advanced stage or prior photocoagulation. Numbers of subjects in each stage are listed in this table.

irrespective of e-GFR status. On the other hand, the rate of disease progression in subjects with albuminuria increased as e-GFR declined. This trend was quite prominent in macroalbuminuric subjects, with more than $70 \%$ of subjects with macroalbumiuria and e-GFR less than $45 \mathrm{~mL} / \mathrm{min} / 1.73$ $\mathrm{m}^{2}$ reaching e-GFR less than $30 \mathrm{~mL} / \mathrm{min} / 1.73 \mathrm{~m}^{2}$ after only three years. In addition, about one-third of the subjects whose e-GFR decreased to less than $30 \mathrm{~mL} / \mathrm{min} / 1.73 \mathrm{~m}^{2}$ after three years exhibited pronounced worsening, from e-GFR above $60 \mathrm{~mL} / \mathrm{min} / 1.73 \mathrm{~m}^{2}$ at baseline.

Forty-four subjects developed CVD within 3 years (Table 4). On multiple logistic regression analysis by the clinical staging based on either e-GFR or AER, only microalbminuria was significantly associated with the development of CVD, of which odds ratio was $2.75(\mathrm{p}<0.01)$.

\section{Discussion}

We examined the risk factors for short-term progression of diabetic nephropathy over a period of three years in this study. Both e-GFR and AER at baseline were significantly associated with decline in GFR to less than $30 \mathrm{~mL} / \mathrm{min} / 1.73$ $\mathrm{m}^{2}$. Subjects with a lower e-GFR status with macroalbuminuria at baseline had a higher rate of progression to GFR less than $30 \mathrm{~mL} / \mathrm{min} / 1.73 \mathrm{~m}^{2}$ after three years. Our study clearly showed that the calculation of e-GFR makes it possible to distinguish high-risk subjects, especially when macroalbuminuria is present.

On the other hand, subjects without albuminuria exhibited a rate of progression of less than $1 \%$ for further decline of e-GFR after three years even with reduced e-GFR level at baseline. The Kidney Disease Outcomes Quality Initiative ${ }^{\mathrm{TM}}$ $\left(\mathrm{KDOQI}^{\mathrm{TM}}\right.$ ) Clinical Practice Guidelines and Clinical Practice Recommendations for Diabetes and Chronic Kidney Disease (10) proposed a table of likelihood of diabetic nephropathy based on staging by GFR and level of albuminuria. However, our study found that clinical staging based on level of albuminuria had greater impact on the development of diabetic nephropathy.

Some questions arise in understanding these findings. First, in this study, the rate of deterioration of diabetic nephropathy with macroalbuminuria was much higher than that in the United Kingdom Prospective Diabetes Study (UKPDS) (11), although strictly speaking UKPDS did not include e-GFR in estimates of renal prognosis. Another possible explanation involves differences in ethnicity, since the Japanese are known to be prone to progression of renal complications (1). 
Table 2. Differences in Baseline Values between the Two Groups Divided according to e-GFR Level after 3 Years

\begin{tabular}{|c|c|c|c|}
\hline & \multicolumn{3}{|c|}{ e-GFR after 3year observation } \\
\hline & e-GFR $>30$ & e-GFR $<29$ & $p$ value \\
\hline age $(y / 0)$ & $59.9 \pm 8.8$ & $59.1 \pm 10.7$ & n.s. \\
\hline gender (male/female) & $865 / 403$ & $29 / 6$ & n.s. \\
\hline BMI & $23.6 \pm 3.8$ & $25.3 \pm 3.8$ & $<0.01$ \\
\hline duration of diabetes mellitus (year) & $10.3 \pm 8.3$ & $14.9 \pm 8.8$ & $<0.01$ \\
\hline systolic blood pressure $(\mathrm{mmHg})$ & $131 \pm 17.4$ & $144 \pm 18.8$ & $<0.01$ \\
\hline diastolic blood pressure $(\mathrm{mmHg})$ & $74.3 \pm 10.7$ & $78.6 \pm 12.5$ & $<0.05$ \\
\hline fasting plasma glucose $(\mathrm{mmol} / \mathrm{L})$ & $9.67 \pm 2.89$ & $9.57 \pm 2.90$ & n.s. \\
\hline $\mathrm{HbA1c}(\%)$ & $8.7 \pm 1.8$ & $9.5 \pm 2.0$ & $<0.01$ \\
\hline total cholesterol $(\mathrm{mmol} / \mathrm{L})$ & $5.28 \pm 0.94$ & $5.78 \pm 1.16$ & $<0.01$ \\
\hline HDL cholesterol (mmol/L) & $1.35 \pm 0.38$ & $1.34 \pm 0.48$ & n.s. \\
\hline triglyceride $(\mathrm{mmol} / \mathrm{L})$ & $1.59 \pm 1.40$ & $1.83 \pm 1.04$ & n.s. \\
\hline hemoglobin $(g / L)$ & $143 \pm 14$ & $131 \pm 17$ & $<0.01$ \\
\hline serum creatinin $(\mu \mathrm{mol} / \mathrm{L})$ & $64.5 \pm 44.2$ & $97.2 \pm 26.5$ & $<0.01$ \\
\hline $\begin{array}{r}\text { e-GFR }\left(30-59 / 60-89 / 90<\mathrm{mL} / \mathrm{min} / 1.73 \mathrm{~m}^{2}\right) \\
\text { at baseline }\end{array}$ & $126 / 797 / 345$ & $25 / 7 / 3$ & $<0.01$ \\
\hline $\begin{array}{r}\text { diabetic nephropathy (none/ } \\
\text { microalbuminuria/ macroalbuminuria) }\end{array}$ & $802 / 379 / 87$ & $1 / 6 / 28$ & $<0.01$ \\
\hline $\begin{array}{r}\text { diabetic retinopathy (none/ background/ } \\
\text { preploliferative, more advanced stage or } \\
\text { prior photocoagulation) }\end{array}$ & $917 / 239 / 112$ & $9 / 11 / 15$ & $<0.01$ \\
\hline prior cardiovascular disease (\%) & 2.2 & 8.1 & $<0.01$ \\
\hline present smoker (\%) & 24.0 & 25.7 & n.s. \\
\hline $\begin{array}{r}\text { renin-angiotensin system blockade } \\
\text { medication (\%) }\end{array}$ & 21.2 & 60.0 & $<0.01$ \\
\hline
\end{tabular}

Diabetic nephropathy is subdivided into none/ microalbuminuria/ macroalbuminuria and diabetic retinopathy into none/ background/ more advanced stage or prior photocoagulation. Numbers of subjects in each stage are listed in this table.

The second question concerns the etiology of renal insufficiency. In this study, we did not perform renal biopsy for determination of pathophysiological status. It is thus possible that other etiologies of renal disease such as nephrosclerosis coexisted with diabetic nephropathy. The existence or not of albuminuria was associated with striking differences in rate of disease progression irrespective of e-GFR level in this study. Although it is natural to suppose that this difference in the findings was associated with differences in underlying etiology, determining the etiology of renal dysfunction in type 2 diabetes mellitus is difficult. Renal biopsy is usually considered if the medical history or the results of urinalysis suggest an etiology other than diabetic nephropathy (10). Those subjects whose e-GFR declined to less than $30 \mathrm{~mL} / \mathrm{min} / 1.73 \mathrm{~m}^{2}$ after three years were in a more advanced clinical stage of diabetic retinopathy at baseline and included a higher proportion of those with prior CVD. This suggests that the renal insufficiency in diabetic subjects is multi-factorial.
The third question is whether three years is long enough to evaluate worsening of renal function of type 2 diabetes. A three-year period does appear to be too short for evaluation of the prognosis of diabetic nephropathy, considering the life-long nature of type 2 diabetes. Our findings do not clearly demonstrate that $\mathrm{CKD}$ in type 2 diabetic subjects without albuminuria does not advance to ESRD. Lower GFRs might have been observed had we continued observation longer. It is thus clear that physicians must exercise with care in following diabetic subjects with CKD. However, a recent report by Rigalleau et al also noted that diabetic subjects with normoalbuminuric renal insufficiency had lower risk of progression to renal insufficiency or death over observation for about three years (12). In their study, e-GFR tended to decrease in the albuminuric subjects, though not to a statistically significant extent. As discussed in their article, this was probably because of the small sample size of their study.

As for the development of CVD, our study showed only 
Table 3. Results of Logistic Regression Analysis of Associations with Estimated GFR Decline after 3 Years

\begin{tabular}{||r|c|c||c|c||c|c||}
\hline & \multicolumn{2}{|c||}{ model A } & \multicolumn{2}{c||}{ model B } & \multicolumn{2}{c||}{ model C } \\
\hline variables & Odds Ratio & $\mathrm{p}$ value & Odds Ratio & $\mathrm{p}$ value & Odds Ratio & $\mathrm{p}$ value \\
\hline $\begin{array}{r}\text { systolic blood pressure } \\
(\mathrm{mmHg})\end{array}$ & 1.036 & $<0.01$ & 1.019 & 0.11 & $/$ & $/$ \\
\hline $\mathrm{HbA1c}(\%)$ & 1.480 & $<0.01$ & 1.389 & $<0.01$ & $/$ & $/$ \\
\hline AER $(\mu \mathrm{g} / \mathrm{min})$ & 1.002 & $<0.01$ & $/$ & $/$ & $/$ & $/$ \\
\hline $\begin{array}{r}\mathrm{e}-\mathrm{GFR} \text { at baseline } \\
(\mathrm{mL} / \text { min/1.73m2) }\end{array}$ & 0.914 & $<0.01$ & $/$ & $/$ & $/$ & $/$ \\
\hline $\begin{array}{r}\mathrm{e}-\mathrm{GFR} \text { at baseline }<60 \\
(\mathrm{~mL} / \text { min/1.73m2) }\end{array}$ & $/$ & $/$ & 10.209 & $<0.01$ & 9.022 & $<0.01$ \\
\hline $\begin{array}{r}\text { presence of } \\
\text { micrialbuminuria }\end{array}$ & $/$ & $/$ & 7.208 & 0.074 & 10.322 & $<0.05$ \\
\hline $\begin{array}{r}\text { presence of } \\
\text { macroalbuminuria }\end{array}$ & $/$ & $/$ & 93.34 & $<0.01$ & 132.274 & $<0.01$ \\
\hline
\end{tabular}

Model A used continuous data, while Model B included nominal variables related to the clinical staging of kidney disease. Model $\mathrm{C}$ was analyzed only with these clinical stagings.

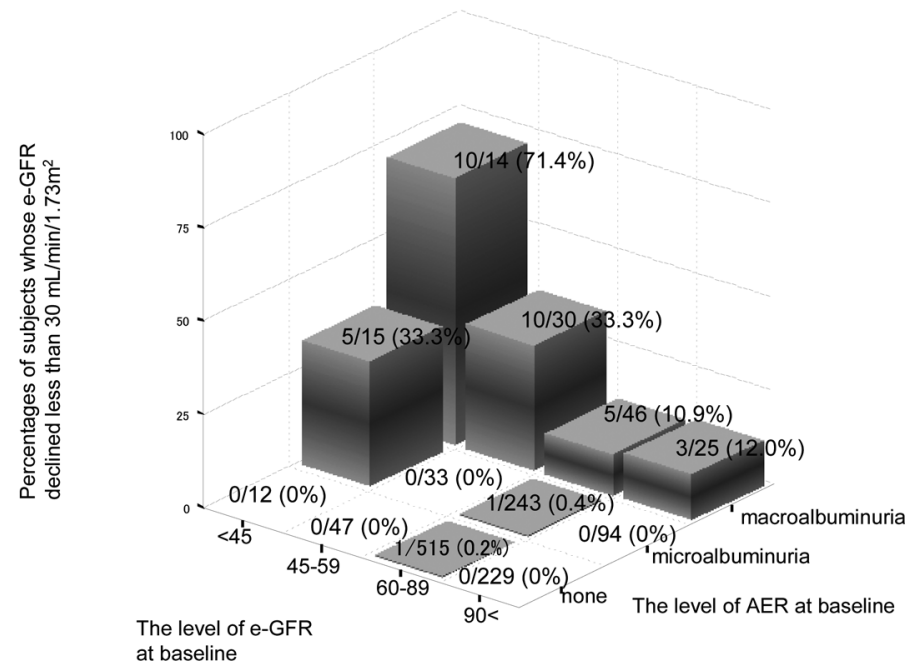

Figure 1. Numbers and percentages of subjects whose estimated GFR declined to lower than 30 $\mathrm{mL} / \mathrm{min} / 1.73 \mathrm{~m}^{2}$ after 3 years. Bars represent percentages, while exact numbers and percentages are indicated near the bar for each category.

microalbuminuria was significantly associated with the development of CVD but neither macroalbuminuria nor e-GFR less than $60 \mathrm{~mL} / \mathrm{min} / 1.73 \mathrm{~m}^{2}$ was associated. The "amountresponse relationship" in albuminuric subjects was vague compared to the risk for the deterioration of renal function but this might result from the small number of subjects with macroalbuminuria. We feel that further research is necessary to reach any conclusion about the CVD risk of macroalbuminuria or decreased GFR.

Regarding harder end-points, Agarwal et al reported differences between e-GFR and proteinurea as a risk factor for progression to ESRD or death (13). In another study by Bruno et al, the increased risk of mortality associated with low e-GFR in type 2 diabetes mellitus was evident only in macroalbuminuric subjects (14). Although the concept of CKD has been useful for understanding the risks for decrease in renal function, it is our belief that individual disease conditions included in CKD and their associated risk factors and etiologies should be individually examined to the extent possible. At least in the case of nephropathy in type 2 diabetes, albuminuria could be a strong risk factor for worsening of renal function, cardiovascular disease, and death. 
Table 4. Numbers and Percentages of Subjects who Developed Cardiovascular Disease within 3 Years

\begin{tabular}{||r|c|c|c||}
\hline e-GFR at baseline \albuminuria & none & microalbuminuria & macroalbuminuria \\
\hline $\mathrm{e}-$ GFR $\geqq 60 \mathrm{~mL} / \mathrm{min} / 1.73 \mathrm{~m}^{2}$ & $14 / 744(1.88 \%)$ & $16 / 337(4.75 \%)$ & $5 / 71(7.04 \%)$ \\
\hline $\mathrm{e}-\mathrm{GFR}<60 \mathrm{~mL} / \mathrm{min} / 1.73 \mathrm{~m}^{2}$ & $2 / 59(3.39 \%)$ & $5 / 48(10.4 \%)$ & $1 / 44(2.27 \%)$ \\
\hline
\end{tabular}

Denominators represent the numbers of subjects in each category and numerators represent the numbers of subjects who developed cardiovascular disease within 3 years. The numbers in parenthesis represent the percentage of subjects who developed cardiovascular disease.

It has been widely reported that RAS blockade prevents further deterioration of diabetic nephropathy (15). Our study showed that the RAS blockade medication was used significantly more frequently in subjects whose renal function worsened in three years. This must be typical bias that the subjects with more severe diseases tended to receive RAS blockade medication more frequently. In our study cohort, over $70 \%$ of hypertensive subjects and around $90 \%$ of hypertensive subjects with macroalbuminuira were being treated with RAS blockers. It thus appears that the usefulness of RAS blockade has been recognized in selecting antihypertensive medications. However, only $42 \%$ of normotensive subjects with macroalbuminuria were being treated with RAS blockers. These rates were much lower than we had expected. Which factors interfered with RAS blockade in these subjects is unclear from our findings. The fluctuating nature of blood pressure, the fear of excessive lowering of blood pressure, and the cost of treatment may limit intensive antihypertensive treatment. However, the finding of an extremely high risk of renal deterioration in association with macroalbuminuria and reduced e-GFR over a relatively short period and the results of a previous interventional study (16,
17) may necessitate stronger antihypertensive treatment. Multifaceted intervention in subjects with type 2 diabetes and microalbuminuria reduced the progression of albuminuria, retinopathy, neuropathy, and composite outcome of CVD events or death $(18,19)$. A similar multifaceted clinical trial using intensive treatment for macroalbuminuric subjects with type 2 diabetes mellitus to prevent the deterioration of renal function should be performed because their kidney dysfunctions progress so rapidly.

There must be some limitations for understanding of this study because this study was performed as a hospital-based cohort study in one hospital. The selection bias, therefore, could not be avoided. And considerable percentages of the subjects were lost during the study period.

In conclusion, our prospective observational cohort study revealed that both clinical staging based on level of AER and that based on reduced e-GFR were significantly associated with further deterioration of renal function. However, albuminuria had a greater odds ratio than reduced e-GFR for deterioration of renal function over a three-year period. Calculation of e-GFR is useful for predicting such deterioration of diabetic nephropathy only when albuminuria is present.

\section{References}

1. Ritz E, Orth SR. Nephropathy in patients with type 2 diabetes mellitus. N Engl J Med 341: 1127-1133, 1999.

2. Yokoyama H, Tomonaga O, Hirayama M, et al. Predictors of the progression of diabetic nephropathy and beneficial effect of angiotensin-converting enzyme inhibitors in NIDDM patients. Diabetologia 40: 405-411, 1997.

3. Ueda H, Ishimura E, Shoji T, et al. Factors affecting progression of renal failure in patients with type 2 diabetics. Diabetic Care 26: 1530-1534, 2003.

4. Hasslacher C, Ritz E, Wahl P, Michael C. Similar risk of nephropathy in patients with type I or type II diabetes mellitus. Nephrol Dial Transplant 4: 859-863, 1989.

5. Go AS, Chertow GM, Fan D, McCulloch CE, Hsu CY. Chronic kidney disease and the risk of death, cardiovascular events, and hospitalization. N Engl J Med 351: 1296-1305, 2004.

6. Anavekar NS, McMurray JJ, Velazquez EJ, et al. Relation between renal dysfunction and cardiovascular outcome after myocardial infarction. N Engl J Med 351: 1285-1295, 2004.

7. Ninomiya T, Kiyohara Y, Kubo M, et al. Chronic kidney disease and cardiovascular disease in a general Japanese population: The Hisayama Study. Kidney Int 68: 228-236, 2005.

8. Irie F, Iso H, Sairenchi T, et al. The relationships of proteinuria, serum creatinine, glomerular filtration rate with cardiovascular dis- ease mortality in Japanese general population. Kidney Int 69: 1264-1271, 2006.

9. Imai E, Horio M, Nitta K, et al. Estimation of glomerular filtration rate by the MDRD study equation modified for Japanese patients with chronic kidney disease. Clin Exp Nephrol 11: 41-50, 2007.

10. KDOQI Clinical Practice Guidelines and Clinical Practice Recommendations for Diabetes and Chronic Kidney Disease. Am J Kidney Dis 49 (2 suppl 2): S12-S154, 2007.

11. Adler AI, Stevens RJ, Manley SE, Bilous RW, Cull CA, Holman RR. Development and progression of nephropathy in type 2 diabetes: The United Kingdom Prospective Diabetes Study (UKPDS 64). Kidney Int 63: 225-232, 2003.

12. Rigalleau V, Lasseur $C$, Raffaitin $C$, et al. Normoalbuminuric Renal-Insufficient Diabetic Patients: A lower-risk group. Diabetes Care 30: 2034-2039, 2007.

13. Agarwal R, Bunaye Z, Bekele DM, Light RP. Competing risk factor analysis of end-stage renal disease and mortality in chronic kidney disease. Am J Nephrol 28: 569-575, 2008.

14. Bruno G, Merletti F, Bargero G, et al. Estimated glomelurar filtration rate, albuminuria and mortality in type 2 diabetes: the Casale Monferrato study. Diabetologia 50: 941-948, 2007.

15. Strippoli GF, Craig M, Deeks JJ, Schena FP, Craig JC. Effects of 
angiotensin converting enzyme inhibitors and angiotensin II receptor antagonists on mortality and renal outcomes in diabetic nephropathy: systematic review. BMJ 9: 828, 2004.

16. Brenner BM, Cooper ME, de Zeeuw D, et al. Effects of losartan an renal and cardiovascular outcomes in patients with type 2 diabetes and nephropathy. N Engl J Med 345: 861-869, 2001.

17. Lewis EJ, Hunsicker LG, Clarke WR, et al. Collaborative Study Group. Renoprotective effect of the angiotensin-receptor antagonist irbesartanin patients with nephropathy due to type 2 diabetes.
N Engl J Med 345: 851-860, 2001.

18. Gaede P, Vedel P, Larsen N, Jensen GV, Parving HH, Pedersen O. Multifactorial intervention and cardiovascular disease in patients with type 2 diabetes. N Engl J Med 348: 383-393, 2003.

19. Gaede P, Vedel P, Parving HH, Pedersen O. Intensified multifactorial intervention in patients with type 2 diabetes mellitus and microalbuminuria: The Steno type 2 randomised study. Lancet 353: 617-622, 1999.

(C) 2009 The Japanese Society of Internal Medicine http://www.naika.or.jp/imindex.html 